\title{
HETEROGENEOUSLY CATALYSED ETHANOLYSIS OF SUNFLOWER OIL IN THE PRESENCE OF PROPYLENE GLYCOL, ETHYL ACETATE AND DIETHYL ETHER AS COSOLVENTS
}

Dušica R. Đokić-Stojanović ${ }^{\star}$, Zoran B. Todorović ${ }^{\text {, Dragan Z. Troter }}{ }^{2}$,

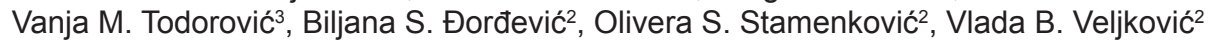

\footnotetext{
${ }^{1}$ Zdravlje Actavis, Leskovac, Serbia

2 Faculty of Technology, University of Niš, Leskovac, Serbia

3 Faculty of Pharmacy, University of Belgrade, Belgrade, Serbia
}

(ORIGINAL SCIENTIFIC PAPER) UDC 665.334.9:662.756.3:66.097
A heterogeneous reaction process using propylene glycol (PEG), ethyl acetate and diethyl ether as cosolvents for the transesterification of sunflower oil with ethanol in the presence of calcium oxide as a catalyst has been developed. Significant results were obtained with propylene glycol as a cosolvent. Under determined reaction conditions ( $\mathrm{CaO}$ concentration, based on the oil weight $1.3736 \mathrm{~mol} \cdot \mathrm{dm}^{-3}$; temperature $70{ }^{\circ} \mathrm{C}$; and ethanol-to-oil molar ratio $\left.12: 1\right)$, the conversion of sunflower oil to fatty acid ethyl esters (FAEE) exceeded $98 \%$ after 120 min, which was 2 times faster than transesterification of sunflower oil without a cosolvent. After initially enhanced ethanolysis, after 180 min ethyl acetate and diethyl ether negatively influenced the reaction rate and the FAEE yield.
Keywords: biodiesel, ethanolysis, sunflower oil, calcium oxide, catalyst, cosolvents.

\section{Introduction}

Biodiesel is a promising alternative energy source with properties similar to diesel. This biofuel is frequently made by alcoholysis of vegetable oils (or animal fats) with a primary aliphatic alcohol, usually methanol or ethanol [1-5]. Catalysts used for this reaction can be homogeneous acidic or basic catalysts, heterogeneous acidic or basic catalysts, or lipases. Homogeneous catalysts are mostly used. The corrosive nature of homogeneous catalysts, their difficult removal from the reaction mixture after the reaction, and water pollution present serious disadvantages [6]. Acid-catalysed reactions are usually slower than base-catalysed [7-8] and may require a large excess of alcohol and high pressure [9]. A greener alternative to chemical transesterification is enzymecatalysed transesterification [10]. Unfortunately, high cost of enzymes, lipase inactivation caused by methanol and impurities in crude and waste oils represent big disadvantages for this type of transesterification [11]. Heterogeneous (solid) catalysts in the biodiesel production provide a number of benefits. The separation of solid catalysts and purification of products are simpler and cheaper, compared to the same processes when homogeneous catalysts are used. Also, the solid catalysts can be used repeatedly, reducing the operating costs [12]. Biodiesel is a mixture of fatty acid alkyl esters. When ethanol is used as a reactant, the resulting mixture will be fatty acid ethyl esters (FAEE) [13-14], and if methanol is chosen as a reactant, the product will be the mixture of fatty acid methyl esters (FAME) [14-15]. The advantage of using ethanol for the alcoholysis of vegetable oils is reflected in its lower toxicity and higher solubility in oils than methanol [13]. Since ethanol has one carbon atom more than methanol, FAEE have a higher heat content and cetane number compared to FAME [14]. In addition, ethanol is obtained from biological raw materials, which is why its use in the synthesis of biodiesel fuel is completely agrarian.

Because of its basicity, low solubility and low price, $\mathrm{CaO}$ is commonly used as a heterogeneous catalyst for biodiesel synthesis from vegetable oils [16]. CaO attracted the attention because of its high catalytic activity [17] and the possibility of multiple use without significant decrease of its catalytic properties [18-19]. In the previous studies $\mathrm{CaO}$ used in the methanolysis of vegetable oils was obtained from different sources [18-23] and from various precursors [24], so the reported optimum reaction conditions are different. Also, quicklime bits represent a very promising catalyst for continuous sunflower oil methanolysis in the continuous flow packed-bed tubular reactor [25].

Based on literature reviews $[12,19]$ it was concluded that the main catalyst in CaO-catalysed ethanolysis is actually basic ethoxide anion which is formed directly and indirectly: (a) $\mathrm{O}^{2-}$ from $\mathrm{CaO}$ extracts $\mathrm{H}^{+}$from the hydroxyl group of ethanol, and (b) $\mathrm{O}^{2-}$ from $\mathrm{CaO}$ extracts $\mathrm{H}^{+}$from water to form $\mathrm{OH}^{-}$, which further extracts $\mathrm{H}^{+}$from ethanol, thus generating ethoxide anion and water, respectively. In step II, the transesterification mechanism of acyl glycerols takes place in

\footnotetext{
*Author address: Dušica R. Đokić-Stojanović, Zdravlje Actavis, Vlajkova 199, 16000 Leskovac, Serbia

E-mail:777dusica@gmail.com

The manuscript received: March, 10, 2016.

Paper accepted: May, 16, 2016.
} 
the presence of ethoxide anions. First, the ethoxide anion attaches to a carbonyl carbon atom of the triacylglycerol (TAG) molecule to form the tetrahedral intermediate. Second, the intermediate picks up an $\mathrm{H}^{+}$ion from $\mathrm{CaO}$ and reacts with ethanol to produce ethoxide anion. Finally, the reallocation of the tetrahedral intermediate results in the production of both biodiesel and glycerol. Lisboa et al. [26] reported that the calcium diglycerolate was stable up to the third reuse cycle. This is not a big problem because the compounds formed after decomposition $\left(\mathrm{CaCO}_{3}\right.$ and $\mathrm{Ca}(\mathrm{OH})_{2}$ ) could be calcinated to form the calcium oxide $(\mathrm{CaO})$, and the glycerol synthesized as a by-product in soybean oil methanolysis can be used to react with calcium oxide to obtain a new batch of calcium diglycerolate. Since the work of Boocock et al. [27], many studies have been performed with the use of various cosolvents in transesterification reactions. Homogeneously catalysed methanolyses are preferred in most of the previous works [16,27-30]. Tetrahydrofuran (THF) has been mainly used as a cosolvent [27, 28, 31], because of its low price, nonreactivity and easy separation from the reaction mixture after compilation of the reaction, since methanol and THF have close boiling points $\left(65^{\circ} \mathrm{C}\right.$ and $67^{\circ} \mathrm{C}$, respectively). THF increases the rate constant of transesterification reactions [28,31], but possesses a tendency to form peroxide during the storage [30], which is a major disadvantage.

Guan et al. [29] suggested dimethyl ether, an environmentally friendly solvent, as a cosolvent for the transesterification process. The same research team [30] tested several cosolvents (THF, dimethyl ether, diethyl ether and tert-butyl methyl ether), and dimethyl ether proved to be the most efficient. Park et al. [32] used fatty acid methyl ester (FAME) as a cosolvent. According to Encinar et al. [33] tert-butyl methyl ether and diethyl ether showed the best potential as cosolvents, compared with various cosolvents (dibutyl ether, diisopropyl ether, tetrahydrofuran, and acetone). Pena et al. [34] studied $n$-hexane as a cosolvent for castor oil transesterificaton with three alkaline catalists $\left(\mathrm{CH}_{3} \mathrm{ONa}, \mathrm{NaOH}\right.$ and $\left.\mathrm{KOH}\right)$. Hancsók et al. [35] studied the production of fatty acid methyl esters (FAME) from frying oil with acid/base-catalysed transesterification with THF and dioxane as cosolvents. Hernando et al. [36] studied the transesterfication of rapeseed and soybean oils combining the use of tert-butyl methyl ether and microwave irradiation to reduce the mass transfer limitation in the first reaction stage. Todorović et al. [37] studied both homogeneously and heterogeneously base-catalysed sunflower oil methanolysis with and without the presence of cosolvents. In the former case, $\mathrm{KOH}$ and THF were used as a catalyst and a cosolvent, respectively. In the latter case, $\mathrm{CaO}$ and various organic solvents such as THF, $n$-hexane, dioxane, diethyl ether, triethanolamine, ethyl acetate and methyl ethyl ketone were employed as a solid catalyst and a cosolvent, respectively. The rate of $\mathrm{KOH}-$ catalysed sunflower oil methanolysis increased with increasing the THF concentration up to $50 \%$ of the oil mass. No effect of THF present at the concentration of $20 \%$ on the rate of $\mathrm{CaO}$-catalysed methanolysis was observed, but at higher THF concentrations, the reaction was delayed and the final fatty acid methyl esters (FAME) yield was decreased. Of all the tested cosolvents, only n-hexane and THF slightly improved the methanolysis reaction in its initial period, triethanolamine and ethyl acetate had no effect, while diethyl ether, dioxane and methyl ethyl ketone negatively influenced the reaction rate and the FAME yield [37]. Sakthivel et al. [38] investigated the effects of residence time and reaction temperature on the yield of fatty acid methyl ester (biodiesel) with and without the presence of biodiesel as a cosolvent. The results showed that the yield of fatty acid methyl esters obtained was almost $20 \%$ higher than the cosolvent free process. The $\mathrm{KOH}$-catalyzed sunflower oil methanolysis in the absence and presence of THF as a cosolvent was investigated by Banković-Ilić et al. [39] in a continuous cocurrent upflow reciprocating plate reactor. In this study, the positive effects of this cosolvent on the Sauter-mean diameter of the dispersed phase, the drop size distribution and the TAG conversion degree in both reactive (methanol/KOH/oil) and non-reactive (methanol/oil) systems were reported.

Despite above mentioned benefits, the use of cosolvents in heterogeneously catalysed methanolysis has been reported in a few papers [21,40-42]. Gryglewicz [21] and Yang and Xie [42] desribed the positive impact of THF on heterogeneosly catalysed methanolysis, while Ilgen et al. [40] and Kim et al. [41] observed an inhibitory effect of THF. Kim et al. [41] also found that methanolysis reaction can be improved in the presence of n-hexane, while Ilgen et al. [40] and Yang and Xie [42] reported a negative effect of $n$-hexane. The observed disagreement on the effect of cosolvents on heterogeneously catalysed transesterification should be investigated in order to be clarified [37].

The present work deals with the ethanolysis of sunflower oil catalysed by the calcinated $\mathrm{CaO}\left(550{ }^{\circ} \mathrm{C}, 2 \mathrm{~h}\right)$ in the presence of various cosolvents. The heterogeneously catalysed ethanolysis of sunflower oil is a threephase reaction system (oil, alcohol and solid catalyst), where mass transfer limitations, due to immiscibility of the reactants, determine the overall reaction rate. An organic solvent added as a cosolvent reduces immiscibility of the reactants and increases the transesterification reaction rate. Calcium oxide and various organic solvents such as propylene glycol (PEG), ethyl acetate and diethyl ether were employed as a solid catalyst and cosolvents, respectively, and the reactions were carried out at the $70{ }^{\circ} \mathrm{C}$ with ethanol-oil molar ratio of $12: 1$. The impact of PEG, ethyl acetate and diethyl ether as a cosolvent on the heterogeneosly $\mathrm{CaO}$ catalysed ethanolysis have been discussed in detail.

\section{Experimental}

Materials

Commercial edible sunflower oil (Dijamant, Serbia) was used. Ethanol (99.8\%) was purchased from La- 
chema (Czech Republic). CaO (extra pure) was from Centrohem (Serbia). CaO was activated before use by

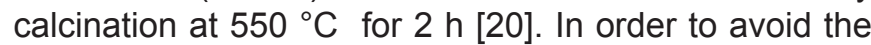
adsorption of water and carbon dioxide from the air on catalytic active sites on the catalyst surface, the activated $\mathrm{CaO}$ was cooled and then stored in a well closed glass bottles in a desiccator containing $\mathrm{CaCl}_{2}$. Also, the following solvents were used: propylene glycol (PEG) (Ph Eur, Meilab, Belgrade, Serbia), ethyl acetate (99.5\%, Merck), diethyl ether (Lachner). The properties of the used cosolvents and ethanol are presented in Table 1.

Table 1. The properties of used cosolvents and ethanol

\begin{tabular}{cccc}
\hline Cosolvent & ETAC $^{\text {a }}$ & DEE $^{\mathrm{b}}$ & PEG $^{\mathrm{c}}$ \\
\hline Density $\left(\mathbf{g} \cdot \mathbf{c m}^{-3}\right)$ & 0.894 & 0.713 & 1.036 \\
Viscosity at $\mathbf{2 0}{ }^{\circ} \mathbf{C}(\mathbf{m P a} \cdot \mathbf{s})$ & 0.45 & 0.24 & 56 \\
Partition coefficients at $\mathbf{2 5}{ }^{\circ} \mathbf{C}(\log \mathrm{P})$ & 0.73 & 0.89 & 0.92 \\
Dipole moment, $\mathbf{D}$ & 1.78 & 1.15 & 3.6 \\
Dielectric constant at $\mathbf{4 0}{ }^{\circ} \mathbf{C}$ & 6.02 & 4.33 & 32 \\
\hline
\end{tabular}

${ }^{\mathrm{a} E T A C}$ - ethyl acetate; ${ }^{\mathrm{b}} \mathrm{DEE}$ - diethyl ether; ${ }^{\mathrm{c}} \mathrm{PEG}$ - propylen glycol.

\section{Heterogeneously catalysed ethanolysis}

The apparatus for heterogeneosly-catalysed ethanolysis consisted of $500 \mathrm{ml}$ three-neck round-bottomed flask, placed in a glass chamber and equipped with a magnetic stirrer and a condenser. Water was circulated through the chamber from a thermostated bath $(70 \pm 1$ $\left.{ }^{\circ} \mathrm{C}\right)$. In these series of experiments, where the effect of different cosolvents ( $20 \%$, based on the mass oil) was studied, the amount of $\mathrm{CaO}$ was corresponding to the concentracion of $1.3736 \mathrm{~mol} \cdot \mathrm{dm}^{-3}$. In all experiments, the catalyst was suspended into ethanol ( $28.76 \mathrm{~g}$; ethanol-to oil molar ratio 12:1) in the reaction flask. The amount of a cosolvent $(9.19 \mathrm{~g})$ was added to the mixture of ethanol and the catalyst, and the reaction flask was shaked for 30 minute. Sunflower oil $\left(45.96 \mathrm{~g}\right.$, at temperature $70 \pm 1^{\circ} \mathrm{C}$ ) was added in the reaction flask, and the measurements of the reaction time began. The samples $(750 \mu \mathrm{L})$ were removed from the reaction mixture during the ethanolysis reaction, immediately quenched by adding the solution of hydrochloric acid $\left(5 \mathrm{~mol} \cdot \mathrm{dm}^{-3}\right)$ to stop the reaction and centrifuged (3500 rpm, $10 \mathrm{~min}$ ). The upper layer (named FAEE fraction) was withdrawn, dissolved in 2-propanol/n-hexane $(5: 4 \mathrm{v} / \mathrm{v})$ in an appropriate ratio and filtered through a $0.45 \mu \mathrm{m}$ Millipore filter. The resulting filtrate was used for a high performance liquid chromatography (HPLC) analysis.

\section{Analitical methods}

Thin layer chromatography (TLC) analysis

In order to perform the qualitative analysis, the composition of each sample of the reaction mixture was estimated by TLC. Solutions and standards were spotted onto a $20 \times 10 \mathrm{~cm}$ plate (Silica gel 60 F254; Merck, Darmstadt, Germany) with a $10 \mu \mathrm{L}$ HP microsyringe in amounts of $5 \mu \mathrm{L}$ of solution per spot. The plates were developed in a glass chambers with an organic mixture of n-hexane/ethyl acetate/acetic acid (90:10:1 v/v/v) [43] and air-dried thoroughly. In order to visualise the spots that developed, iodine vapor was used [44].

High performance liquid chromatography (HPLC) analysis

For quantitative determination, the composition of the FAEE fraction (both glycerides and FAEE) of the selected samples of the reaction mixture was determined by the modified HPLC method by Holčapek et al. [45]. An HPLC chromatograph (Agilent 1100 Series) equipped with a micro vacuum degasser, a binary gradient system, a thermostated column compartment and a variable wavelength detector was employed. For separation, a Zorbax Eclipse XDB-C 18 column $(4.6$ X $150 \mathrm{~mm}$ with $5 \mu \mathrm{m}$ particle size) was used. The column temperature was constant at $40{ }^{\circ} \mathrm{C}$. In all experiments, the injection volume of $20 \mu \mathrm{L}$ and flow rate of $1 \mathrm{~mL} / \mathrm{min}$ were applied. The mobile phase was methanol (reservoir $A$ ) and 2-propanol/n-hexane (5:4 v/v; reservoir B). A linear gradient from $100 \% A$ to $40 \% A+60 \%$ B in 15 min was employed, and the components were detected at $205 \mathrm{~nm}$. By using the standard mixture of FAEE and the standard glycerides, the calibration curves were prepared and used for the quantification of the FAEE and the glycerides present in the selected samples.

\section{Results and discussion}

In order to investigate the impacts of some cosolvents on the $\mathrm{CaO}$-catalysed ethanolysis of sunflower oil, in all experiments the amount of cosolvent was $20 \%$ of the mass oil and the amount of the catalyst corresponded to the concentration of $1.3736 \mathrm{~mol} \cdot \mathrm{dm}^{-3}$.

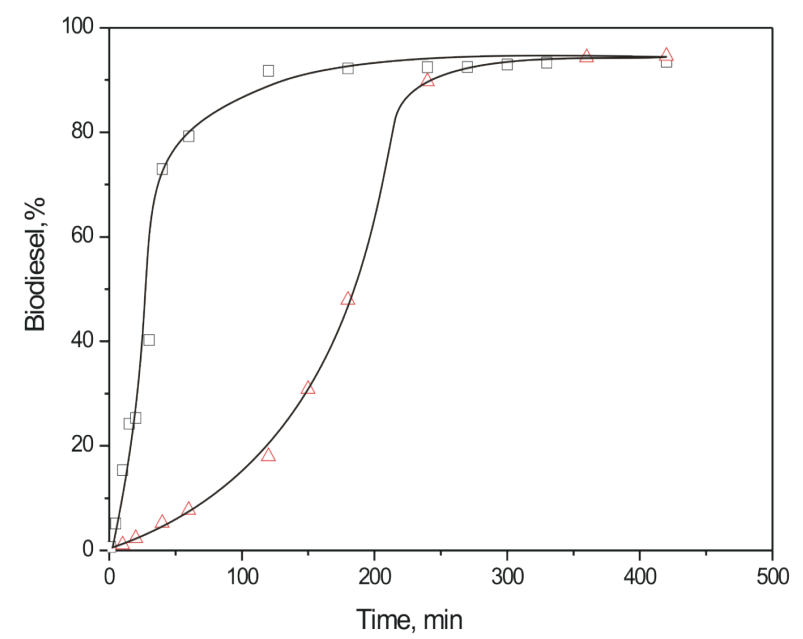

Figure 1. The variations of the FAEE yield with the progress of sunflower oils ethanolysis catalysed by $\mathrm{CaO}(20 \%$, based on the oil weight): no cosolvent - 0 ; with propylene glycol (PEG) as cosolvent - $\square$. Reaction conditions: catalyst concentration, based on the oil weight $1.3736 \mathrm{~mol} \cdot \mathrm{dm}-3$; temperature $70{ }^{\circ} \mathrm{C}$; and ethanol-to-oil molar ratio 12:1. 
Figure 1 shows the variations of the FAEE yield during the ethanolysis reaction catalysed by $\mathrm{CaO}$ without a cosolvent and in the presence of propylene glycol propylene glycol (PEG) as a cosolvent. PEG significantly accelerates the ethanolysis reaction. The FAEE yield in the presence of PEG as a cosolvent in 20 minutes was $25.3 \%$, which is 10.83 times more than in the reaction without a cosolvent. After 40 minutes, the FAEE yield was $72.9 \%$, which was 14 times more than in the reaction without a cosolvent, and after 180 minutes the FAEE yield was $92.2 \%$, which was 2 times more than in the reaction without a cosolvent. This means that the ethanolysis reaction is almost complete after 180 minutes from the reaction start. It was 3 hours less for the same FAEE yield if the reaction which was carried out without a cosolvent.

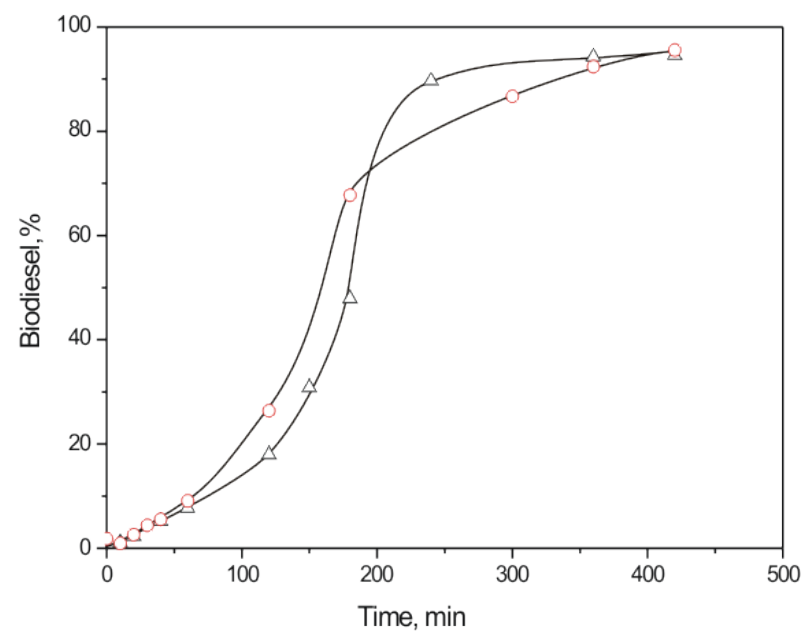

Figure 2. The variations of the FAEE yield with the progress of sunflower oils ethanolysis catalysed by $\mathrm{CaO}(20 \%$, based on the oil weight): no cosolvent - $\circ$; with ethyl acetate as cosolvent - $\square$. Reaction conditions: catalyst concentration, based on the oil weight $1.3736 \mathrm{~mol} \cdot \mathrm{dm}^{-3}$; temperature $70^{\circ} \mathrm{C}$; and ethanol-tooil molar ratio $12: 1$

As seen from Figure 2, the ethyl acetate has no significant effect on the ethanolysis reaction rate. In the first 180 min the FAEE yield is a little bit higher than the FAEE yield in the ethanolysis without cosolvent. After 180 minutes, the ethanolysis reaction with ethyl acetate as a cosolvent was delayed and the final FAEE yield was decreased. The assumption was that ethyl acetate provided an extra ethyl group due to its degradation, so the same reaction was carried out in the absence of ethanol. After 6 hours, the quantity of the oil was the same as at the beginning, meaning that the reaction was unsuccessful, proving that the dissociation of ethyl acetate does not occur, and ethyl group which reacts with triglycerides in order to form FAEE originates only from ethanol. As it can be seen from Figure 2, the ethyl acetate has no significant impact on the ethanolysis reaction rate. Up to 180 minutes from the reaction start, the FAEE yields are a little larger than the FAEE yields in the ethanolysis without a cosolvent. After 180 minutes, the ethanolysis reaction with ethyl acetate as a cosolvent was delayed and the final FAEE yields were decreased.

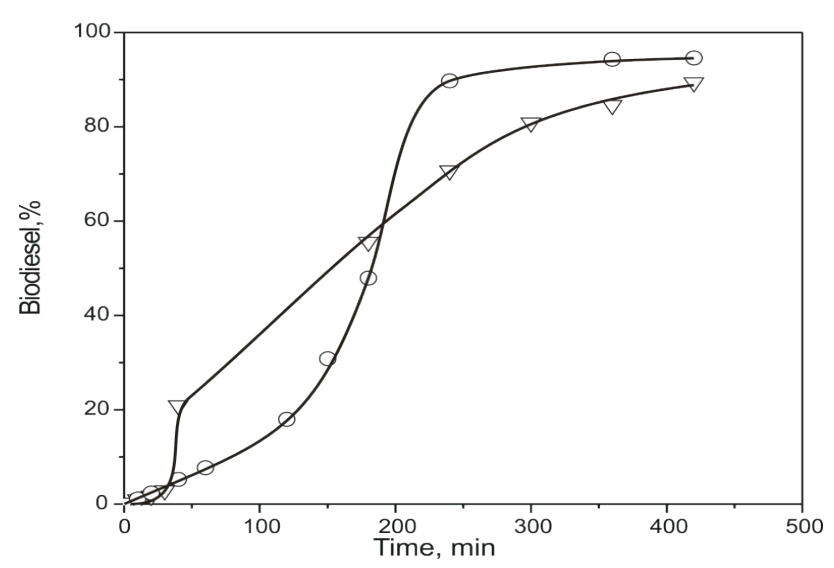

Figure 3. The variations of the FAEE yield with the progress of sunflower oils ethanolysis catalysed by $\mathrm{CaO}(20 \%$, based on the oil weight): no cosolvent - $\odot$; with diethyl ether as cosolvent $\square$. Reaction conditions: catalyst concentration, based on the oil weight $1.3736 \mathrm{~mol} \cdot \mathrm{dm}^{-3}$; temperature $70^{\circ} \mathrm{C}$; and ethanol-to-oil molar ratio 12:1.

Figure 3 represents the variations of the FAEE yield during the ethanolysis reaction catalysed by $\mathrm{CaO}$ without a cosolvent and in the presence of diethyl ether as a cosolvent. After 40 minutes, the FAEE yield in the presence of diethyl ether was $20.9 \%$, which was 4 times more than the yield from the reaction without a cosolvent. After 180 minutes from the ethanolysis reaction start with diethyl ether as a cosolvent, the final FAEE yield was less than the FAEE yield in the ethanolysis reaction catalysed by $\mathrm{CaO}$ without a cosolvent. Because the diethyl ether has a lower density than the reaction medium, its addition increased the reaction rate at the beginning of the reaction due to the easier mass transfer. But, as the ethanolysis reaction progressed, the final FAEE yield with diethyl ether as a cosolvent decreased due to a dilution effect of the reactants.

It is obvious from Figure 4 that the activity of all tested cosolvents in the ethanolysis reaction catalysed by $\mathrm{CaO}$ act according to the following order: PEG > ethyl acetate $>$ diethyl ether. PEG strongly accelerates the ethanolysis reaction. Under the same reaction condition, the reaction time was 3 hours shorter, compared to the reaction carried out in the absence of PEG. After 20 min from the beginning of the reaction, the ethanolysis catalysed by $\mathrm{CaO}$ and with PEG as a cosolvent provided FAEE yield of $25.3 \%$, which was higher than the FAEE yield reported when ethanolysis was carried out without PEG (2.3\%). 


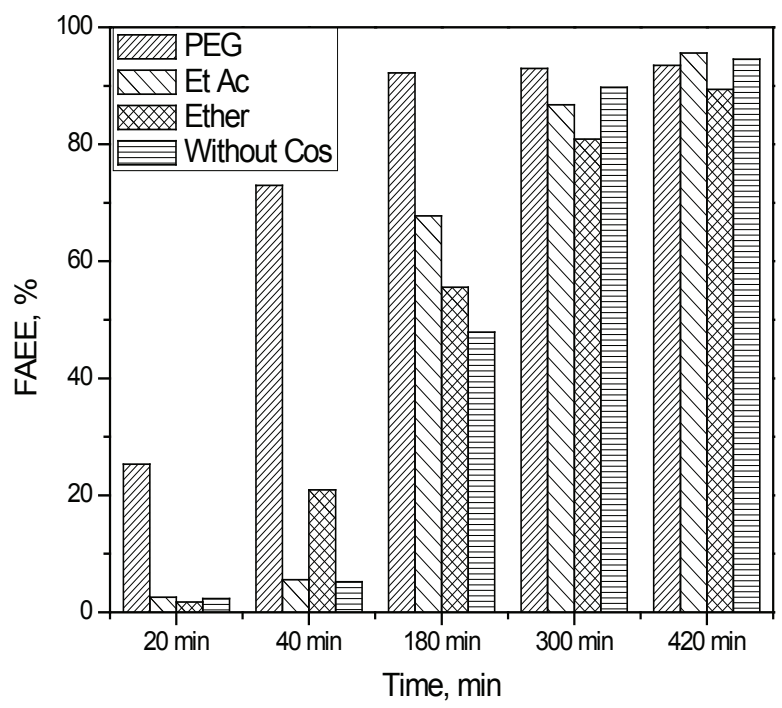

Figure 4. The FAEE yield obtained by catalytic reaction with $\mathrm{CaO}$ as catalyst without cosolvents and in catalytic reactions with $\mathrm{CaO}$ as a catalyst with the following cosolvents: propylene glycol , ethyl acetate and diethyl ether . Reaction conditions: catalyst concentration, based on the oil weight 1.3736 $\mathrm{mol} \cdot \mathrm{dm}^{-3}$; temperature $70^{\circ} \mathrm{C}$; and ethanol-to-oil molar ratio 12:1.

The other investigated cosolvents are less affective. Ethyl acetate and diethyl ether increaced the reaction rate only at the start of the reaction, mostly because their presence in the reaction medium reduced immiscibility of the reactants (oil and alcohol), thus producing nearly homogeneous solution. In addition, their presence in the reaction medium diminish the density of the reaction mixture, so that the mass transfer is easier. After 20 minutes from the reaction start the ethanolysis catalysed by $\mathrm{CaO}$ and with ethyl acetate as a cosolvent provided FAEE yield of $2.6 \%$, which was just slightly more than the FAEE yield obtained when the ethanolysis reaction was carried out without a cosolvent $(2.3 \%)$. For the same time duration, the FAEE yield of $1.7 \%$ was reported for the reaction with $\mathrm{CaO}$ as a catalyst and diethyl ether as a cosolvent. It is interesting that, after 40 minutes from the reaction start, the FAEE yield with diethyl ether as a cosolvent was $20.9 \%$, which was 8 times higher than the reported FAEE yield for the reaction when ethyl acetate was chosen as a cosolvent $(2.6 \%)$. The possible cause for this effect are the density and viscosity of the diethyl ether, which have a dominant impact on the mass transfer of the reactants. As the reactions continued, after 180 minutes both ethyl acetate and diethyl ether inhibited the reactions. This can be explained by their possible blockage of the active sites of $\mathrm{CaO}$ crystals' surface, which results in preventing the formation of calcium ethoxide that catalyses the reaction. In addition, the dilution effect of the reactants occurs.

\section{Conclusion}

The CaO-catalysed ethanolysis of sunflower oil was investigated with and without different cosolvents in order to determine whether cosolvents can influence the final FAEE yield and the reaction rate. This study confirmed the positive effect of the tested propylene glycol as a cosolvent on the $\mathrm{CaO}$-catalysed sunflower oil ethanolysis. This reaction was completed beyond 3 hours prior to the original $\mathrm{CaO}$-catalysed reaction without a cosolvent. Both ethyl acetate and diethyl ether increaced the initial reaction rate, but as the ethanolysis progressed, after 180 min. cosolvents inhibited the ethanolysis. However, further studies are needed in order to optimize the operation conditions for $\mathrm{CaO}$-catalysed ethanolysis of sunflower oil with propylene glycol as a cosolvent which strongly accelerated the reaction.

\section{Acknowledgment}

This work has been funded by the Ministry of Education, Science and Technological Development of the Republic of Serbia (Project III 45001).

\section{References}

[1] E. F. Aransiola, T. V. Ojumu, O. O. Oyekola, T. F. Madzimbamuto, D. I. O. Ikhu-Omoregbe, A review of current technology for biodiesel production: State of the art, Biomass and Bioenergy, 61 (2014) 276-297.

[2] M. Mittelbach, C. Remschmidt, Biodiesel the comprehensive handbook, 2nd ed. Boersedruck Ges.m.b.H., Vienna, Austria, 2005.

[3] P. T. Vasudevan, M. Briggs, Biodiesel production-current state of the art and challenges, Journal of Industrial Microbiology \& Biotechnology, 35(5) (2008) 421-430.

[4] D. Narayanan, Y. Zhang, M. S. Mannan, Engineering for sustainable development (ESD) in biodiesel production, Process Safety and Environmental Protection, 85(5) (2007) 349-359.

[5] O. S. Stamenković, A. V. Veličković, V. B. Veljković, The production of biodiesel from vegetable oils by ethanolysis: Current state and perspectives, Fuel, 90(11) (2011) 31413155.

[6] D. Y. C. Leung, X. Wu, M. K. H. Leung, A review on biodiesel production using catalyzed transesterification, Applied Energy, 87(4) (2010) 1083-1095.

[7] W. Liu, P. Yin, X. Liu, S. Zhang, R. Qu, Biodiesel production from the esterification of fatty acid over organophosphonic acid, Journal of Industrial and Engineering Chemistry, 21 (2015) 893-899.

[8] K. A. Shah, J. K. Parikh, K. C. Maheria, Use of sulfonic acid-functionalized silica as catalyst for esterification of free fatty acids (FFA) in acid oil for biodiesel production: An optimization study, Research on Chemical Intermediates, 41(2) (2015) 1035-1051.

[9] P. M. Ejikeme, I. D. Anyaogu, C. L.Ejikeme, N. P. Nwafor, C. A. C. Egbuonu, K. Ukogu, J. A. Ibemesi, Catalysis in biodiesel production by transesterification processes-an Insight, E-Journal of Chemistry, 7(4) (2010) 1120-1132.

[10] L. P. Christopher, H. Kumar, V. P. Zambare, Enzymatic 
biodiesel: Challenges and opportunities, Applied Energy, 119(12) (2014) 497-520.

[11] V. Singh, D. K. Chaudhary, I. Mani, P. K. Dhar, Recent advances and challenges of the use of cyanobacteria towards the production of biofuels, Renewable and Sustainable Energy Reviews, 60 (2016) 1-10.

[12] D. M. Marinković, M. V. Stanković, A. V. Veličković, J. M. Avramović, M. R. Miladinović, O. S. Stamenković, V. B. Veljković, D. M. Jovanović, Calcium oxide as a promising heterogeneous catalyst for biodiesel production: Current state and perspectives, Renewable and Sustainable Energy Reviews 56 (2016) 1387-1408.

[13] J. M. Encinar, J. F. González, J. J. Rodrígez, A. Tejedor, Biodiesel fuels from vegetable oils: transesterification of Cynaracardunculus L. oils with ethanol, Energy Fuels, 16(2) (2002) 443-450.

[14] S. J. Clark, L. E. Wagner, M. D. Schrock, P. G. Piennaar, Methyl and ethyl soybean esters as renewable fuels for diesel engines, Journal of the American Oil Chemists' Society, 61(10) (1984) 1632-1638.

[15] M. K. Lam, K. T. Lee, A. R. Mohamed, Homogeneous, heterogeneous and enzymatic catalysis for transesterification of high free fatty acid oil (waste cooking oil) to biodiesel: A review, Biotechnology Advances, 28(4) (2010) 500-518.

[16] B. Yoosuk, P. Udomsap, B. Puttasawat, P. Krasae, Improving transesterification activity of $\mathrm{CaO}$ with hydration technique, Bioresource Technology, 101(10) (2010) 37843786.

[17] L. Zhao, Z. Qiu, S. M. Stagg-Williams, Transesterification of canola oil catalyzed by nanopowder calcium oxide, Fuel Processing Technology, 114 (2013) 154-162.

[18] X. Liu, H. He, Y. Wang, S. Zhu, X. Piao, Transesterification of soybean oil to biodiesel using $\mathrm{CaO}$ as a solid base catalyst, Fuel, 87(2) (2008) 216-221.

[19] M. L. Granados, M. D. Z. Poves, D. M. Alonso, R. Mariscal, F. C. Galisteo, R. Moreno-Tost, J. Santamaría, J. L. G. Fierro, Biodiesel from sunflower oil by using activated calcium oxide, Applied Catalysis B: Environmental, 73(34) (2007) 317-326.

[20] V. B. Veljković, O. S. Stamenković, Z. B. Todorović, M. L. Lazić, D. U. Skala, Kinetics of sunflower oil methanolysis catalyzed by calcium oxide, Fuel, 88(9) (2009) 1554-1562.

[21] S. Gryglewicz, Rapeseed oil methyl esters preparation using heterogeneous catalysts, Bioresource Technology, 70(3) (1999) 249-253.

[22] C. Reddy, V. Reddy, R. Oshel, J. G. Verkade, Roomtemperature conversion of soybean oil and poultry fat to biodiesel catalyzed by nanocrystalline calcium oxides, Energy Fuels, 20(3) (2006) 1310-1314.

[23] A. Demirbas, Biodiesel from sunflower oil in supercritical methanol with calcium oxide, Energy Conversion and Management, 48(3) (2007) 937-941.

[24] Y. B. Cho, G. Seo, D. R. Chang, Transesterification of tributyrin with methanol over calcium oxide catalysts prepared from various precursors, Fuel Processing Technology, 90(10) (2009) 1252-1258.

[25] M. R. Miladinović, O. S. Stamenković, V. B. Veljković, D. U. Skala, Continuous sunflower oil methanolysis over quicklime in a packed-bed tubular reactor, Fuel 154 (2015) 301-307.

[26] F. d. S. Lisboa, F. R. da Silva, C. S. Cordeiro, L. P. Ramos, F. Wypych, Metal glycerolates as catalysts in the transesterification of refined soybean oil with methanol under reflux conditions, Journal of the Brazilian Chemical Society, 25(9) (2014) 1592-1600.

[27] D. G. B. Boocock, S. K. Konar, V. Mao, H. Sidi, Fast onephase oil-rich processes for the preparation of vegetable oil methyl esters, Biomass and Bioenergy, 11(1) (1996) 43-50.

[28] F. Ataya, M. A. Dubé, M. Ternan, Single-phase and twophase base-catalyzed transesterification of canola oil to fatty acid methyl esters at ambient conditions, Industrial \& Engineering Chemistry Research, 45(15) (2006) 5411 5417.

[29] G. Guan, K. Kusakabe, N. Sakurai, K. Moriyama, Transesterification of vegetable oil to biodiesel fuel using acid catalysts in the presence of dimethyl ether, Fuel, 88(1) (2009a) 81-86.

[30] G. Guan, N. Sakurai, K. Kusakabe, Synthesis of biodiesel from sunflower oil at room temperature in the presence of various cosolvents, Chemical Engineering Journal, 146(2) (2009b) 302-306.

[31] G. R. Kumar, R. Ravi, A. Chadha, Kinetic studies of base-catalyzed transesterification reactions of non-edible oils to prepare biodiesel: the effect of co-solvent and temperature, Energy Fuels, 25(7) (2011) 2826-2832.

[32] J.-Y. Park, D.-K. Kim, Z.-M. Wang, J.-S. Lee, Fast biodiesel production with one-phase reaction, Applied biochemistry and biotechnology, 154(1-3) (2009) 246-252.

[33] J. M. Encinar, J. F. González, A. Pardal, G. Martínez, Transesterification of rapeseed oil with methanol in the presence of various co-solvents, In: Proceedings Venice 2010, Third international symposium on energy from biomass and waste, Venice, Italy, 8-11 November 2010 Italy: CISA, Environmental Sanitary Engineering Centre; 2010.

[34] R. Pena, R. Romero, S. L. Martinez, M. J. Ramos, A Martinez, R. Natividad, Transesterification of castor oil: effect of catalyst and co-solvent, Industrial \& Engineering Chemistry Research, 48(3) (2009) 1186-1189.

[35] J. Hancsók, F. Kovács, M. Krár, Production of vegetable oil fatty acid methyl esters from used frying oil by combined acidic/alkali transesterification, Petroleum \& Coal, 46(3) (2004) 36-44.

[36] J. Hernando, P. Leton, M. P. Matia, J. L. Novella, J. Alvarez-Builla, Biodiesel and FAME synthesis assisted by microwaves: homogeneous batch and flow processes, Fuel, 86(10-11) (2007) 1641-1644.

[37] Z. B. Todorović, O. S. Stamenković, I. S. Stamenković, J. M. Avramović, A. V. Veličković, I. B. Banković-llić, V. B. Veljković, The effects of cosolvents on homogeneously base-catalyzed methanolysis of sunflower oil, Fuel, 107 (2013) 493-502.

[38] S. Sakthivel, S. Halder, P. D. Gupta, Influence of co-solvent on the production of biodiesel in batch and continuous process, International Journal of Green Energy, 10(8) (2013) 876-884.

[39] I. B. Banković-llić, Z. B. Todorović, J. M. Avramović, A. V. Veličković, V. B. Veljković, The effect of tetrahydrofuran on the base-catalyzed sunflower oil methanolysis in a continuous reciprocating plate reactor, Fuel Processing Technology, 137 (2015) 339-350.

[40] O. Ilgen, A. N. Akin, N. Boz, Investigation of biodiesel production from canola oil using Amberlyst-26 as a catalyst, Turkish Journal of Chemistry, 33(2) (2009) 289294.

[41] H.-J. Kim, B.-S. Kang, M.-J. Kim, Y. M. Park, D.-K. Kim, 
J.-S. Lee, K.-Y. Lee, Transesterification of vegetable oil to biodiesel using heterogeneous base catalyst, Catalysis Today, 93-95 (2004) 315-320.

[42] Z. Yang, W. Xie, Soybean oil transesterification over zinc oxide modified with alkali earth metals, Fuel Processing Technology, 88(6) (2007) 631-638.

[43] M. Kaieda, T. Samukawa, T. Matsumoto, K. Ban, A. Kondo, Y. Shimada, H. Noda, F. Nomoto, K. Ohtsuka, E. Izumoto, H. Fukuda, Biodiesel fuel production from plant oil catalyzed by Rhizopus oryzae lipase in a watercontaining system without an organic solvent, Journal of Bioscience and Bioengineering, 88(6) (1999) 627-631.
[44] E. Stahl, Dunshicht Chromatographie, Springer-Verlag, Berlin, 1967, p. 362.

[45] M., Holčapek, P., Jandera, J., Fischer, B., Prokeš, Analytical monitoring of the production of biodiesel by high-performance liquid chromatography with various detection methods, Journal of Chromatography A, 858(1) (1999) 13-31.

Izvod

\section{HETEROGENO KATALIZOVANA ETANOLIZA SUNCOKRETOVOG ULJA U PRISUSTVU POLIETILEN GLIKOLA, ETIL ACETATA I DIETIL ETRA KAO KOSOLVENATA}

Dušica R. Đokić-Stojanović1, Zoran B. Todorović², Dragan Z. Troter², Vanja M. Todorovići ${ }^{3}$ Biljana S. Đorđević2 , Olivera S. Stamenković ${ }^{2}$ Vlada B. Veljković2

1 Zdravlje Actavis, Leskovac, Srbija

2 Tehnološki fakultet, Univerzitet u Nišu, Leskovac, Srbija

3 Farmaceutski fakultet, Univerzitet u Beogradu, Beograd, Srbija

U radu je opisana heterogena transesterifikacija suncokretovog ulja sa etanolom i kalcijum oksidom kao katalizatorom u prisustvu polietilen glikola (PEG), etil acetata i dietil etra kao kosolvenata. Najpovoljniji rezultati su dobijeni sa polietilen glikolom kao kosolventom gde je, pod određenim reakcionim uslovima (koncentracija $\mathrm{CaO}$, računata u odnosu na masu ulja $1.3736 \mathrm{~mol} \cdot \mathrm{dm}^{-3}$, temperatura $70{ }^{\circ} \mathrm{C}$ i molarni odnos etanol:ulje 12:1), konverzija suncokretovog ulja u etil estre masnih kiselina (FAEE) dostigla vrednost od 98\% nakon 120 minuta, što je 2 puta brže od transesterifikacije suncokretovog ulja bez prisustva kosolventa. Etil acetat i dietil etar poboljšavaju reakciju etanolize na početku, ali, kako reakcija napreduje, posle 180 minuta, njihovo prisustvo u reakcionoj smeši negativno utiče na brzinu reakcije i prinos etil estrara masnih kiselina (FAEE).
(ORIGINALNI NAUČNI RAD)

UDK 665.334.9:662.756.3:66.097

Ključne reči: biodizel, etanoliza, suncokretovo ulje, kalcijum-oksid, katalizator, kosolventi. 